\title{
Impact of Management by Objectives [MBO] on the Employee Productivity in Vodafone Ghana
}

\author{
Article by Sadiya Ibrahim Aminu \\ $M B A$, Texila American University \\ E-mail: sadiyaibrahimu@gmail.com
}

\begin{abstract}
The objective of the study is to establish the impact that MBO (Management by Objectives) has on employee productivity.

$M B O$ is a Management tool where by the managers of an organization sit with their subordinates to agree on the objectives or goals of the organization; set targets, follow the targets, monitor and then evaluate the targets.

Many of today's organization have been able to meet their goals because there is a clear understanding of what the mission and vision of the organization is. Also, there is a clear strategy which aligns with the mission of the organization.

MBO was made popular by the Management guru, Peter Druker in his 1954 book titled 'The Practice of Management'. It also became further popular in the 70s through the $90 \mathrm{~s}$ and is still popular.

The study tries to establish the relationship between understanding the objectives by employees/managers on one hand and employee productivity on the other hand. Vodafone Ghana was taken as a case study. A total of 36 employees responded to the questionnaires/interviews granted. Questionnaires and oral interviews were used as sources of primary data.

The overwhelming majority of the employees that responded agreed or even strongly agreed that MBO has a positive impact on employee productivity.

The company was privatized about a decade ago where the majority ownership was taken by Vodafone.

Soon after acquisition, Vodafone began to implement management tools that saw the firm's operational efficiency further increasing.

One of such management tools implemented is the $\mathrm{MBO}$, and which has worked for the firm.

The relationship between the managers and employee in objective setting was seen to be crucial in the productivity of both the employees and the organization.
\end{abstract}

Keywords: Management, Objectives, Employee, Productivity, Impact, Organization.

\section{Introduction}

Management of an organization requires modern management tools in order to help achieve its objectives.

Management is defined as 'doing things through people and with the people'. Objective is what the organization strives to achieve. These objectives can be sales volumes, quality, cost reduction, production efficiency, raw materials usage, promptness to work by staff, service delivery, etc.

MBO is a management tool whereby managers and subordinates agree to organization's targets. In this case, personal goals are converted to organizational goal as the achievement of set targets is in itself motivating.

Prior to MBO, many organizations have in the past strived to achieve set targets but this has been difficult due to one reason or the other. Where other management tools have not yielded positive results, MBO had to step it to enable the organization achieve its set targets. 
MBO has proved useful in many organizations that have adopted it. Managers and employees agree to organizational objectives and remain focused and committed to the goals. MBO is result driven, in that employees strive to achieve goals they set for themselves.

However, for an MBO model to work effectively the managers and employees must have understood the objectives of the organization and their actions are in direct congruence to the objectives. Employees are therefore involved in planning, control and decision making of the organization.

It is generally believed that the employees, when carried along by their managers, seem to have higher productivity in the tasks assigned to them. However, a lot depends on the situation and this should determine how the employees are 'carried along'.

The application of McGregor's theory Y becomes significant under the MBO model. MBO works better with theory $\mathrm{Y}$ which believes that employees like work and are motivated by their achievements (on the contrary, theory $\mathrm{X}$ believes that human beings are generally lazy and have to be compelled to work). Therefore, for the MBO model to work effectively or be practicable, the environment should be theory Y oriented.

MBO is therefore a good management tool that enhances productivity. Also, it is flexible and employees are given the chance and opportunity to contribute to the settings of the objectives. Since employees are involved in the objective setting, it is quite natural that that they follow and strive to achieve the goals they have set. Individual goals are converted to into organizational goals and vice versa.

Managements require so many tools in order to be able to manage businesses on a daily basis. One of many such ways is the popular MBO. As explained earlier, it is a means by which superiors and subordinates identify areas of responsibility with the intended objective, and with an intention of meeting the objective in the most efficient manner. MBO has proved to work well in solving attention-directing questions. Once standards are set and rewards are also set for those standards, employees seem to be motivated by those standards set and they also strive hard to achieve such results.

MBO is seen by many as a framework by which the organization can ultimately see light at the end of the tunnel, i.e. achieve its strategic goals. It is a kind of a guide as to what goals the firm wants to achieve and the means to go about it, with clear measurements of the objectives.

MBO is very much about output in relation to input. Therefore, it is efficiency-oriented. Outputs have to be measured against input and that gives indication as to whether or not management should pursue the objectives. The objectives are not cast in stone as they can be reviewed and altered at any time if they seem not to be working effectively.

In general, MBO should have the following features:

- The managers sit with their subordinates from time-to-time to ensure that the subordinates understand clearly the goals of the firm and map out how these goals will be achieved. This can be done through retreats, for example.

- The goals set should not be too many at a time in order to achieve maximum efficiency. The less the number of goals, the better the chances of success.

- Management should keep rewarding successes achieved by employees. This will further encourage them to perform better. Due to possible lack of motivation, employees were less productive during the pre-privatization era, before introduction of MBO.

- All units of an organization should have a thorough understanding of the goals of the organization in order to have goal congruence at the organizational level. It is only when employees move in one direction that goal congruence can be met.

- From time -to-time review the processes for possible improvements.

For MBO to be effective, the employees have to understand the objectives and must be committed to these objectives.

For Vodafone Ghana, MBO is meant to increase productivity of the employees/firm, which it did. 


\section{Research methodology}

In order for an effective result, some methodology was used in obtaining and analyzing data. Primary source of data collection used were questionnaires and interviews. A total of thirty-six (36) employees responded to questionnaires and/or interviewed.

Vodafone Telecom is one of the most organized and orderly establishments in Ghana. Therefore, it is more convenient to obtain data from here that many other organizations. Hence, the main reason for selecting Vodafone Ghana for this study. Vodafone Ghana provides fixed line, mobile and data services

\section{Research design}

The section is concerned with the design and methodology adopted for the study. It basically defines the research design, population and sample size determination sources of data, questionnaire/interview administration. A research design can also be termed as formulated framework for a plan of action and the particular procedures to follow.

A research design aims to assist the researcher to follow the guidelines for his/her research work. The research design also involves some of the major decision taken by the researcher as well as the difficulties, techniques and the efficient use of resources by the researcher.

For a fair representation of data and the results obtained, random sampling was used to collect data. Thus, this ensured that whatever outcome obtained will be representative of the entire population when projected. This is a simple process and does not require any human interference.

Sampling techniques date back many centuries when carrying out studies as, in many cases, it is not possible to study an entire population within a given space of time.

\section{Population}

The sample selected cuts across the various strata of the employees of Vodafone Ghana, with no regard to rank, position or social standing. Also, samples were from both genders.

Thus, the result obtained can be projected to represent the entire population in the organization.

One problem encountered is that out of total of 50 questionnaires and/or interviews granted, only the 36 mentioned above responded. The response rate is therefore $72 \%$.

Another problem was, even for those that responded, there was a lot of reluctance and time wasting before a response can be achieved. This caused some delay in gathering the reviewing the data.

Other issues included fear of revealing official information by staff due to ethical concerns, etc.

\section{Sources of data}

Data was collected from two main sources - primary data and secondary data.

\section{Primary sources of data}

As stated earlier, these were questionnaires and oral interviews conducted with the employees. This is a first-hand source of data obtained from the staff of Vodafone Ghana. Interviews and interviews were conducted with outmost confidentiality.

The interviews/questionnaires were developed based on the stated objectives of the study. A five-point scale was used thus: 5 - strongly agree, 4- agree, 3- undecided/indifferent, 2- disagree, 1 - strongly disagree.

The interviews and questionnaires cut across all departments.

\section{Secondary sources of data}

Other than the primary data, other sources were also used to collect data. These are the secondary sources of data. They include mainly references from books and journals regarding the subject matter.

Also, by observing the employees over time, it was noticed that those that participated in objective setting with their managers seemed more enthusiastic in carrying out their assignments. 
DOI: 10.21522/TIJMG.2015.SE.19.01.Art006

ISSN: $2520-310 \mathrm{X}$

\section{Data analysis}

The data so received is to be analyzed in order to make a meaningful meaning out of the various amounts of data. The data so gathered is grouped and re-grouped in order to make meaning to the users of the information.

The questionnaires were designed in such a way that they were easy, straightforward and clear to understand. A Likert-type scale was used to group and interpret the data. After grouping, data was tabulated and presented.

\section{Results of research}

This section tries to depict the findings from the responses from the respondents of the questionnaires and interviews.

The following MBO scenarios were linked with the questionnaires and the interview; performance based on objectives set together, zeal to carry out work by the employees with little or no supervision, satisfaction derived from achieving the results. It is obvious that MBO has a significant positive impact on employees' productivity.

As will be seen in later sections, the overwhelming majority agreed or strongly agreed that MBO has an impact on the achievement/productivity, based on objectives set.

The employees also have the zeal to carry out their tasks when objectives are agreed between them and their managers. The employees also derive satisfaction from achieving the targets set.

\section{Discussion}

This section deals with the in-depth feedback from the respondents. As mentioned earlier, 36 respondents took part in the survey and the details of the responses are further explained in tabular forms in a later section.

In the questionnaires and during the interviews, the respondents were made to concentrate in the three areas where $\mathrm{MBO}$ is seen to have impact - performance/productivity, zeal to carry out work and personal satisfaction.

\section{Impact on performance}

Out of the 36 respondents, 21 strongly agreed that MBO has an impact on performance. This represents $58 \%$ of the population. Also, 8 respondents agreed to this representing another $22 \%$. Therefore, a total of $70 \%$ either agreed or strongly agreed with this.

Three (3) respondents are indifferent - representing 8\%, while 2 respondents disagreed - representing $6 \%$ of the population. Another 2 respondents or $6 \%$ also strongly disagreed.

\section{Zeal to carry out work}

Nineteen (19) respondents strongly agreed that MBO has a positive impact on the zeal to carry out the work, representing $52 \%$ of the population. Additional 9 respondents agreed, representing $25 \%$ of the population. Therefore, those that either strongly agreed or agreed combined represent $77 \%$ of the population.

Four of the respondents are indifferent - representing $11 \%$ of the population. Two disagreed representing $6 \%$ of the population, while another two strongly disagreed - representing another $6 \%$.

\section{Satisfaction derived}

Seventeen (17) respondents strongly agreed that MBO has an effect on satisfaction derived by objective setting. This represents $47 \%$ of the population. Eleven (11) respondents agreed, representing $30 \%$ of the population. Those that either strongly agreed or agreed collectively represent $77 \%$ of the population.

Four respondents are indifferent - representing $11 \%$ of the population. Two disagreed representing $6 \%$, while another two strongly disagreed - also representing $6 \%$. 
Overall, from the above it can be seen that the overwhelming majority have at least agreed that MBO has an impact on the operations of Vodafone Ghana.

\section{Conclusion}

It is clear that Vodafone Ghana has taken assessment of itself through a SWOT analysis (strengths, weaknesses, opportunities and threats). Previously, there may have been internal weaknesses during the time the company was wholly government-owned, before the company was privatized about a decade ago. Before privatization, the company (then Ghana Telecom) was unlikely to have adopted MBO; hence the firm was not efficient in its operations.

It may also be that the firm was previously adopting the scientific management approach, according to Fredrick Tailor. This approach may be the wrong approach for Ghana Telecom considering modern day businesses where some flexibility is in vogue and is creating success for many organizations. Rigidity is no longer a principle of management. Vodafone Ghana management is obviously flexible in their approach now.

In her book titled "The Giving of Orders", Mary Follet outlined that governance should have some form of flexibility. She outlines that an appropriate decision is the one in which it is depersonalized. In this manner, management and employees are objective and they convert personal goals to organizational goals. There should always be a good balance between the objectives of the employees and those of the enterprise. This is what Vodafone Ghana have tried to achieve, from the results of the study.

According to Peter Druker, objectives are set along with employees, which should have the following characteristics; challenging, motivating, communication and feedback, reward and performance-related, people-oriented.

The organization also adopted the S.M.A.R.T. goals approach (specific, measurable, attainable, realistic and time- bound). There has also been employee participation and power sharing among the employees.

According to B\&FT Online, Vodafone Ghana amassed 20 key awards in 2017 - highlighting a year in which the company consolidated its position as a company of choice in Ghana.

The telecommunications sector underwent key changes; notably, increased competition, market consolidation and a heightened demand for choice by customers. Despite all these, Vodafone was unrelenting in its quest to provide unmatched experience for customers whilst stepping up its community investment initiatives.

Among the key awards won included Program of the Year - Healthline (CIMG), Best Brand of the Year (UKGCC), Best Advert of the Year (CIMG), Industry Personality of the Year - CEO (GITTA), Best in Employee Relations (HR Focus) and Top 50 Corporate Women Leaders in Ghana.

G. Mensah, Director for External Affairs at Vodafone Ghana said:" These are testament to the commitment we continue to put in to ensure we constantly reflect what we stand for as a company. A new year has begun and we will not rest on our laurels in delivering on our promise of an exciting future of endless possibilities for our customers."

Vodafone has begun the new year on a great note by extending the popular promotion. Customers can now share airtime purchased via Vodafone Cash with five other people and experience an empowerment of being part of a caring family.

However, Vodafone Ghana should note that adopting MBO in itself does not cure all the organization's problems, as in many cases employees do not seem to understand what the organization's objectives are in the first place.

It is also advisable for other organizations in the country to try to emulate Vodafone in the steps taken so far to adopt MBO and other governance practices. This will further encourage competitiveness as well as give benefit to the consumer in enjoying efficient and effective service delivery.

This research has brought out many good attributes of MBO in running an organization. MBO is seen to promote professionalism and ethics as it covers issues such as transparency (setting of goals together), 
DOI: 10.21522/TIJMG.2015.SE.19.01.Art006

ISSN: $2520-310 \mathrm{X}$

fairness (agreeing the objectives), objectivity (realistic goals), independence (goals not imposed to the employees) and responsibility (goal congruence between organizational goals and personal goals), etc.

MBO will have to align with the strategy, mission and vision of the organization in order to be effective. Where the organization wants to be in the next $5-10$ years has to be communicated and well understood to the workers, otherwise MBO can only become an academic exercise. Once the "script" of mission and vision is communicated and understood to the employees, the rest in objective setting will become seamless.

In reality, the success of MBO requires each manager to draw up what is expected of them in their various units in line with company strategy. This has to be understood by all the other employees in order for the objectives to be met within the stipulated time.

\section{The process of $\mathrm{MBO}$ is as in the following steps;}

- Set the organization's objectives. This is knowing what the goals are.

- Cascade the objectives to employees so that workers are aware of their responsibilities. This can be achieved by discussions with the employees.

- Monitor the employees while they carry out their tasks. This can give a true idea of the zeal that the employees have while carrying out their tasks.

- Evaluate the employees' performance to ascertain if they are going according to plan. Where performance is not going according to plan, re-direction can take place. It is possible that some of the employees dis not understand the objectives set, in the first place.

- Reward performance. This serves as a motivational effect and it is an essential part of MBO

\section{Advantages of MBO}

- There is commitment by both the managers and the employees.

- It serves as a direction to the attainment of organizational goal. There is consistency in goals.

- Serves as motivation when employees achieve result.

- The objectives of the company are in constant view.

- Helps to avoid wastages and inefficiencies

- Helps management to be more creative by thinking ahead.

\section{Disadvantages of MBO}

- When goals are not understood by employees, then MBO is ineffective.

- It should not be relied upon if planning is poor

- Eventually, employees and their managers get involve in paperwork other than the real issue of attaining the organizational goals.

- If it becomes annual or quarterly ritual, then MBO will fail.

- When there is no clear division of responsibility, then MBO will fail.

Figures and tables

Table 1. Effect of MBO on the achievement of performance based on objectives sets together (managers/employees)

\begin{tabular}{|l|l|l|}
\hline Position & Population & Percentage (\%) \\
\hline Strongly agree (5) & 21 & 58 \\
\hline Agree (4) & 8 & 22 \\
\hline Indifferent (3) & 3 & 8 \\
\hline Disagree (2) & 2 & 6 \\
\hline
\end{tabular}


Texila International Journal of Management

Special Edition Apr 2019

\begin{tabular}{|l|l|l|}
\hline Strongly (1) & 2 & 6 \\
\hline Total & 36 & 100 \\
\hline
\end{tabular}

Table 2. Effect of MBO on carrying out tasks by the employees with little or no supervision

\begin{tabular}{|l|l|l|}
\hline Position & Population & $\begin{array}{l}\text { Percentage } \\
(\%)\end{array}$ \\
\hline Strongly agree (5) & 19 & 52 \\
\hline Agree (4) & 9 & 25 \\
\hline Indifferent (3) & 4 & 11 \\
\hline Disagree (2) & 2 & 6 \\
\hline Strongly (1) & 2 & 6 \\
\hline Total & 36 & 100 \\
\hline
\end{tabular}

Table 3. Effect of MBO on satisfaction derived from achieving results

\begin{tabular}{|l|l|l|}
\hline Position & Population & Percentage (\%) \\
\hline Strongly agree (5) & 17 & 47 \\
\hline Agree (4) & 11 & 30 \\
\hline Indifferent (3) & 4 & 11 \\
\hline Disagree (2) & 2 & 6 \\
\hline Strongly (1) & 2 & 6 \\
\hline Total & 36 & 100 \\
\hline
\end{tabular}

\section{References}

[1]. Antoni, C. (2005), Management by Objectives - an Effective Tool Teamwork? International Journal of Human Resources Management,16(2).

[2]. Arthur, C.C. (1975), Personnel Management, New York: Alexander Hamilton Institute Press.

[3]. Dinesh, D. and Palmer, E. (1998), Management by Objectives and the Balanced Scorecard: Will Rome Fall Again? Management Decisions, 36(5/6).

[4]. Drucker, P. (1979), The Practice of Management, London: Heinemann Publishers. 